\section{The suicide rate in Northern Ireland}

\section{DeAR Sirs}

In his report on the 1987 annual meeting in Belfast (Bulletin. March 1988, 12, 114-115), Geoffrey Wallis stated "the suicide rate went down in 1979 but has been rising since 1981".

In a paper which I presented at the meeting, entitled 'A comparative study of suicide in Northern Ireland and England and Wales since 1960', I pointed out that the suicide rate fell by $35 \%$ in 1970 , the first full year of the civil disturbances, continued to fall until 1972 and then stabilised until 1976. Since then there has been a steady increase in the number of suicides in Northern Ireland and since 1983 the rate has, for the first time ever, approximated to that of England and Wales (in 1983 the suicide rate in Northern Ireland was 92.0 per million population and in England and Wales 86.7 per million population).

I postulated that the fall in the rate in the early 1970s was typical of a trend documented many times over the last 100 years in various war settings. Thus one explanation could be the development of elaborate social support systems, which gave help to those with depression and other psychological difficulties. The rise since 1976 could perhaps be seen as resulting from people becoming inured to 'an acceptable level of violence'; which has also tended to be largely directed towards specific target groups, such as members of the security forces, rather than the population as a whole, as was previously the case. The social support systems have gradually become rather less significant in people's lives and a 'normal' suicide pattern appears to have emerged.

Further research would need to examine the pattern of accidental deaths and 'open verdicts', as well as looking at the suicide rate among specific groups of individuals. However, the basic trend of a fall in the suicide rate in the early 1970 s and a substantial increase since 1976, in parallel with a similar increase in England and Wales, seems likely to be confirmed.

Purdysburn Hospital

Belfast

P. MCGARRY

\section{Activities of the College overseas: Overseas Desk}

DeAr Sirs

I am delighted to hear that the College is thinking of setting up an 'Overseas Desk' (Bulletin, February 1988, 12, 70) concerned with education, recognition of experience and training, manpower and professional training. These matters are important and worth pursuing but it is essential that the College sets certain priorities.

There are a number of psychiatric association meetings and conventions in North America and I doubt the need for the College to be very active in the areas of education, training, etc. here. What would be useful would be to have a meeting of the North American Chapter of the College along with a major annual meeting like that of the American Psychiatric Association, Canadian Psychiatric Association, etc., which is already occurring to some extent.

I feel that the College should concentrate its resources and energies more on the developing countries. In this regard I wholeheartedly support Dr Mubbashar's suggestions on how this can be arranged (Bulletin, February 1988). I feel the College should give top priority to education and research, training of residents, and linking up university departments of psychiatry in Britain and other developed countries with university departments in developing countries. The College could also facilitate exchange of visiting professors through endowments and pharmaceutical companies' support. A fund could be set up whereby distinguished clinicians/academicians could visit educational centres in developing countries (I believe the Royal College of Physicians and Surgeons of Canada has a travelling fellowship programme on these lines). Also, the same could be arranged for distinguished clinicians, academicians from developing countries.

I realise that the initiative for most of the above programmes should come from the members and fellows of the College in each country. It is also important that the above activities are conducted and promoted in a sensitive way which does not raise charges of 'Neo Colonisation'. The College however, is ideally placed to coordinate the various educational, training activities mentioned above.

MOHan P. DAS

MHMR Authority of Brazos Valley

PO Box 4588

Bryan, Texas 77805, USA

We are grateful to Dr Das for this helpful contribution towards the activities of the College overseas, and his letter will be discussed in detail. Certainly we would see the main educational impetus being towards developing countries, and his suggestions for this are excellent.

Professor ANDrew Sims

Dean

\section{Impact of low NHS funding on junior psychiatrists}

\section{DeAr Sirs}

The Collegiate Trainees' Committee are concerned at the current low levels of NHS funding and the impact this may be having on junior psychiatrists training and practice.

As part of the College's information gathering exercise, I would be grateful if trainees could send me specific details of the effects of cut backs or chronic low funding in their District.

Potential problems include: difficulty in obtaining funding for study leave, effects on junior medical staff of reduced staffing in other disciplines, e.g. CPNs or day hospital nursing staff and delay by employing authorities in filling vacant posts. 
Our major concern is of course the impact of low funding on the quality of care which we can offer our patients. Junior doctors are particularly well placed to monitor the effects of reduced facilities on in-patients, particularly in long-term wards. It is important that details of difficulties are given as accurately as possible and the information will be passed on to the DHSS as part of the College's campaign to protect and develop psychiatric services. The information could be given to me directly or through the local CTC representative whose name will be available from Mrs Jean Wales at the College.

PETER RICE

Chairman

Collegiate Trainees' Committee

\section{Is there a role for community clinical medical Dear SiRS officers in mental handicap?}

In his letter to the Bulletin (March 1988), Dr D. A. Spencer posed the question whether there is a need to create a new post of community medical officer for mentally handicapped adults. In my opinion, the answer is an emphatic 'No'. The integration of medically handicapped people is difficult enough; there is no need to make it more difficult by creating a new category of medical posts and depriving them of normal services which are available to other groups of the population. In fact, the surveys by Beckitt, Searle \& Wright" conclude: "The primary care of people with mental handicap living in an institution but due for community resettlement soon, could well be met by family doctors. People with mental handicap do not make significantly greater demands on primary medical care services than other people of the same age groups, nor is the pattern of their consultations different in terms of urgency, venue, nature or timing."

Discharging a large number of mentally handicapped people from hospitals into the list of one GP does not helpif the patients are spread over a large area involving the practice of all the GPs in a district, the GPs as well as members of the community respond with much more interest and enthusiasm. Of course, every GP should be consulted before sending patients to him or her. Support by core members of the Community Handicap Team (e.g. community nurses and social workers) is a great help to the mentally handicapped people and the GPs.

I would reiterate ${ }^{2}$ " ... the initiative of disengaging from non-psychiatric problems and making other specialists and general practitioners interested and involved in the problems of the mentally handicapped must come from psychiatrists in mental handicap. Surely, there is no need for 'new doctors' but there is a need for better use of existing doctors of all disciplines."

Windsor Unit

D. Chakraborti

King's Lynn, Norfolk
REFERENCES

${ }^{1}$ Beckitt, D., Searle, G. F. \& Wright, E. C. (1987) What sort of doctors do people with mental handicap need? British Journal of Clinical \& Social Psychiatry, 5, 38-42.

${ }^{2}$ ChAKRABORTI, D. (1987) Consultant psychiatrist in mental handicap. Bulletin of the Royal College of Psychiatrists, 11, 132.

\section{Does Hollywood need the MRCPsych? \\ DeAR SiRS}

Psychiatrists have usually been portrayed in the cinema as tolerant, patient and paternal. Having seen 'The House of Games', a recent success in Britain and America, we are irritated that a new cliché has been created.

The leading character in this film is a female psychiatrist. She is unemotional, highly successful, but with a life so devoid of excitement that she must enter the world of her patient to be fully satisfied. Dr Margaret Ford (Lindsay Crouse) wears expensive but boring clothes and speaks in a precise clipped fashion: only glaringly obvious Freudian slips indicate that there is a beating heart below the surface. The author of a book called Driven (supposedly about addictions), she sees patients on an individual basis in a large State Hospital. Her only friend is a large German psychoanalyst (the matriarchal version of the old cliche, perhaps?) who helpfully interprets Dr Ford's frequent parapraxes.

Dr Ford is seeing a gambler for individual psychotherapy. Despite her years of experience, she commits two cardinal sins of such treatment-collusion and over-involvement. She believes her patient's threat of suicide (because he owes a large amount of money) and agrees to help him financially.

She is drawn into the dark mysterious world of expert conmen. With her initial false moves, we are not surprised to find that, at the end, she has been the victim of a huge conjob. When she turns to petty theft, she merely confirms our suspicions that she was not cut out to be a psychiatrist after all. Indeed her continuously flattened affect might lead us to question her mental stability.

In an effort to create an interesting character, David Mamet has tried too hard. We found ourselves wishing for the melodrama of psychiatry of less 'realistic' films, rather than this contrived female psychiatrist.

So it is only cinema? This is merely irritating. American film-directors need to take a closer look at their psychiatrists, and indeed, at their women. Will the MRCPsych become a necessary qualification in Hollywood? Perhaps it should be bestowed honorarily on those directors and actors who portray our profession with credibility!

AIsLing CAMpbell

RAYMOND TRAVERS EAMONN MOLONEY

National Drug Advisory and Treatment Centre,

Jervis Street, Dublin I 